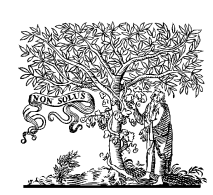

ELSEVIER

\title{
EDITORIAL
}

\section{A Message from the Chair}

As I begin my term as Chair of the College's Board, I reflect on the amount of time, effort and work those who have held this chair have done in making what the College is today. The advancement of the College to the position it has obtained in advancing wound care throughout the world is a significant accomplishment and attests to the concept of uniting the diversity of wound care specialists in a community dedicated to the advancement of wound care: a concept that I hope to further as Chair of the College.

One of the first things that I want to do as the newly elected chair is to thank those on the board who have offered to serve as chair of the committees that have contributed so much to the success of the college. Specifically Chet Evans and chair of the Education Committee, Don Mrdjenovich who has graciously accepted both the chair of the Bylaws and Procedures Committee as well the chair of the Corporate Relations Committee, Rose Hamm chair of the Nominating Committee, Todd Goodman who will chair the Web Committee and Barry Creighten who will chair the Membership Committee.
There are two other people who need to be recognized for their contributions to the college. Richard Simman who will continue to act as editor-in-chief of the Journal of the American College of Clinical Wound Specialists and Tony McNevin the Executive Director of the College. Both have taken on Herculean tasks which have significantly advanced the College to where it is today.

I would hasten to add that this is not a college of board members and chairs. It is made up of many talented disciplines whose contributions to the college will further the goals that we have set. Adding the letters FACCWS after ones name denotes an achievement that is recognized in the wound care community, however, actions are louder than words. As such, I would ask every member to contribute to the college by serving on a committee, contributing an article to the journal, foster regional and national meetings of the college and encouraging associates to join the college.

I look forward to advancing the college with all its members and thank you for your support and dedication,

Sincerely, 